05.2

\title{
Проявление линии Видома при микроволновых измерениях увлажненных перекисью водорода сорбентов
}

\author{
(C) А.А. Гурулев, А.О. Орлов \\ Институт природных ресурсов, экологии и криологии СО РАН, Чита, Россия \\ E-mail: Igc255@mail.ru
}

Поступило в Редакцию 18 августа 2021 г.

В окончательной редакции 6 октября 2021 г.

Принято к публикации 14 октября 2021 г.

Для глубоко переохлажденной объемной воды известны аномалии термодинамических величин вблизи линии Видома, локуса повышенных флуктуаций энтропии и плотности. Выполнено измерение отраженной мощности микроволнового излучения на частоте $18 \mathrm{GHz}$ от образца силикатного сорбента, увлажненного раствором перекиси водорода. В эксперименте наблюдались вариации регистрируемой отраженной мощности излучения в интервале от -46 до $-47^{\circ} \mathrm{C}$, определяемые структурными изменениями жидкости. Показано, что флуктуации параметров воды вблизи линии Видома проявляются в изменении не только термодинамических, но и электрофизических величин.

Ключевые слова: линия Видома, вторая критическая точка, нанопористые материалы, перекись водорода, микроволновый диапазон.

DOI: 10.21883/PJTF.2022.02.51921.18995

В настоящее время известно 75 аномалий объемной воды, из них наиболее яркие связаны с переохлажденной водой. Примером является недавнее открытие второй критической точки (фазового перехода жидкость-жидкость), существующей при температуре вблизи $-60^{\circ} \mathrm{C}$ и давлении $\sim 100 \mathrm{MPa}[1-3]$. Из этой точки в однофазную область исходит линия Видома, локус повышенных флуктуаций энтропии и плотности. Для давления $0.1 \mathrm{MPa}$ температура $(T)$ на линии Видома равна $-45^{\circ} \mathrm{C}$. В многочисленных экспериментах установлено аномальное возрастание теплоемкости при постоянном давлении $\left(C_{p}\right)$, изотермической сжимаемости, коэффициента объемного расширения и некоторых других физических величин при приближении к линии Видома. Существование линии Видома было подтверждено в эксперименте по рассеянию излучения рентгеновского лазера фемтосекундной длительности на каплях воды микронных размеров, испаряющихся в вакууме [4]. Все аномалии объясняются в рамках двухструктурной модели воды, состоящей из кластеров LDL (воды низкой плотности) и HDL (воды высокой плотности) [1,3]. В этой модели в отличие от предшествующих кластеры находятся в непрерывном изменении их структуры на пикосекундных временах. Их концентрация и размеры зависят от температуры, и все особенности физических свойств жидкой объемной воды во всем интервале ее существования определяются взаимодействием двух видов кластеров. Кластеры HDL преобладают при температурах выше температуры на линии Видома; напротив, концентрация кластеров LDL возрастает при понижении температуры жидкости. Однако для отрицательных температур по данному вопросу еще мало экспериментальных данных, что связано с трудностью получения глубоко переохлажденной объемной метастабильной воды. Кроме того, можно отметить отсутствие исследований аномалий электромагнитных характеристик переохлажденной воды вблизи линии Видома. Их обнаружение позволило бы использовать хорошо разработанные методы измерения электрофизических параметров сред.

Чтобы получить глубокое переохлаждение объемной воды, во многих работах используют увлажненные нанопористые силикатные сорбенты. В них бо́льшая часть воды, как показано в $[5,6]$, близка по своим характеристикам к объемной воде до температур около $-70^{\circ} \mathrm{C}$. Кроме того, добавление в воду солей или других растворимых в ней веществ может затормозить кристаллизацию, что позволяет достичь более низких температур. В некоторых случаях холодная вода растворов сохраняет свойства объемной переохлажденной воды и ее характерные аномалии. Например, недавно были открыты водные растворы трифторацетата гидразиния $\left(\mathrm{N}_{2} \mathrm{H}_{5} \mathrm{TFA}\right)$, которые не кристаллизуются до температуры их стеклования. На каплях этого раствора получено аномальное возрастание $C_{p}$, характерное для поведения на линии Видома, в узком интервале температур вблизи $-87^{\circ} \mathrm{C}$ (при атмосферном давлении) [7].

Цель настоящей работы заключается в исследовании изменения диэлектрических характеристик холодных растворов при переходе через линию Видома. Измерялись мощность $(P)$ отраженного микроволнового излучения от увлажненных растворами силикатных сорбентов. В качестве увлажняющего раствора была использована перекись водорода $\left(\mathrm{H}_{2} \mathrm{O}_{2}\right)$. Система $\mathrm{H}_{2} \mathrm{O}_{2}-\mathrm{H}_{2} \mathrm{O}$ имеет две точки эвтектики вблизи $-(52-54)^{\circ} \mathrm{C}$ для весовой концентрации перекиси 45 и 61\% [8]. По этой причине для нее легче переохладить заметное количество жидкости до температур ниже $-45^{\circ} \mathrm{C}$.

Схема установки для измерения отраженной мощности микроволнового излучения приведена на рис. 1. 


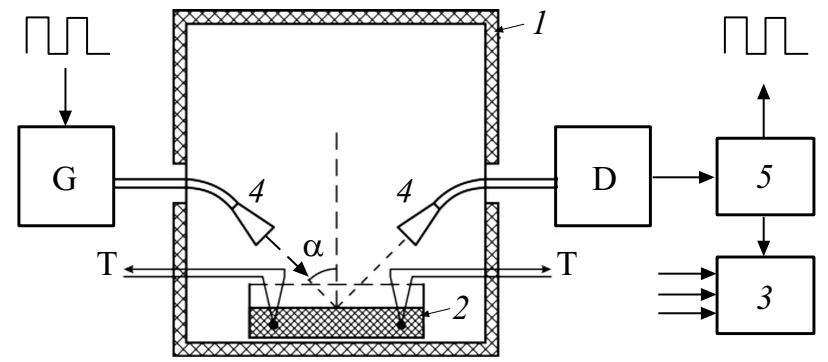

Рис. 1. Схема установки для температурных измерений коэффициента отражения от слоя силикагеля, увлажненного растворами. 1 - климатическая камера ESPEC-SU, 2 - металлическая кювета с образцом, 3 - система сбора данных, 4 - рупорные антенны, 5 - блок обработки. G - генератор микроволнового излучения, D - детектор.

В эксперименте понижали температуру в камере 1 от комнатной до $-68^{\circ} \mathrm{C}$ по линейному закону. Измеряемый образец в виде увлажненного порошка помещался в металлическую кювету 2 с плоским дном. Температура образца измерялась при помощи трех термопар (T), имеющих постоянную времени $0.5-1 \mathrm{~s}$. Кювету герметизировали крышкой из тонкой радиопрозрачной пленки. Излучение генератора (G) с использованием пирамидальной рупорной антенны 4 на частоте $18 \mathrm{GHz}$ направлялось на образец под углом $\alpha$ к нормали от поверхности на горизонтальной поляризации. Угол $\alpha$ был выбран равным $45^{\circ}$. Расстояние от плоскости раскрыва антенн до поверхности образца составляло $10 \mathrm{~cm}$. Размер апертуры антенн $5 \times 3 \mathrm{~cm}$. Размеры кюветы $16 \times 12 \mathrm{~cm}$ выбирались бо́льшими, чем размер пятна диаграмм направленности антенн на поверхности образца. В схеме регистрации с кристаллическим детектором (D) использовался синхронный демодулятор 5. Для этого излучение генератора модулировалось с использованием опорного сигнала. Измеряемые сигналы регистрировались системой сбора информации фирмы Agilent. Точность измерения температуры составляла $1^{\circ} \mathrm{C}$.

В представленной методике определяется изменение мощности отраженного от плоского слоя увлажненного порошка сорбента толщиной в несколько миллиметров. При изменении температуры образца в случае возникновения в нем фазовых переходов или изменений диэлектрической проницаемости вблизи линии Видома наблюдаются вариации коэффициента отражения. Для регистрации аномалий находилась производная $\partial P / \partial T$. Скорость измерений составляла 2 отсчета в секунду, скорость изменения температуры образца $0.2-0.1^{\circ} \mathrm{C} / \mathrm{min}$. Отношение приращений $P$ и $T$ вычислялось для времени $0.5 \mathrm{~s}$.

Для экспериментов использовали концентрированную перекись водорода (40\%), а также растворяли гидроперит, который в растворе распадается на перекись водорода и карбамид (с содержанием перекиси 35\% от исходной массы). Как выяснилось, полученные резуль- таты легче интерпретировать при использовании гидроперита. В специальном эксперименте по термометрии с растворами в случае чистой перекиси водорода наблюдались две точки эвтектики (ниже $-52^{\circ} \mathrm{C}$ ), а также скачки производной $\partial P / \partial T$ при $-29^{\circ} \mathrm{C}$ на графиках в области нагревания образца. Эти особенности отсутствовали для случая увлажнения сорбента раствором гидроперита.

Результаты измерений представлены на рис. 2 и 3. В образцах использовался силикагель марки КСКГ со средним размером пор $8 \mathrm{~nm}$, увлажненный раствором гидроперита с весовой концентрацией в воде $32 \%$. Ожидаемая весовая концентрация $\mathrm{H}_{2} \mathrm{O}_{2}$ в растворе $\sim 11.2 \%$, а в образце $\sim 1.8 \%$. Толщина слоя силикагеля в виде порошка с размерами частиц $\sim 100 \mu \mathrm{m}$ составила 4-5 mm. Расчетное значение скин-слоя для увлажнен-
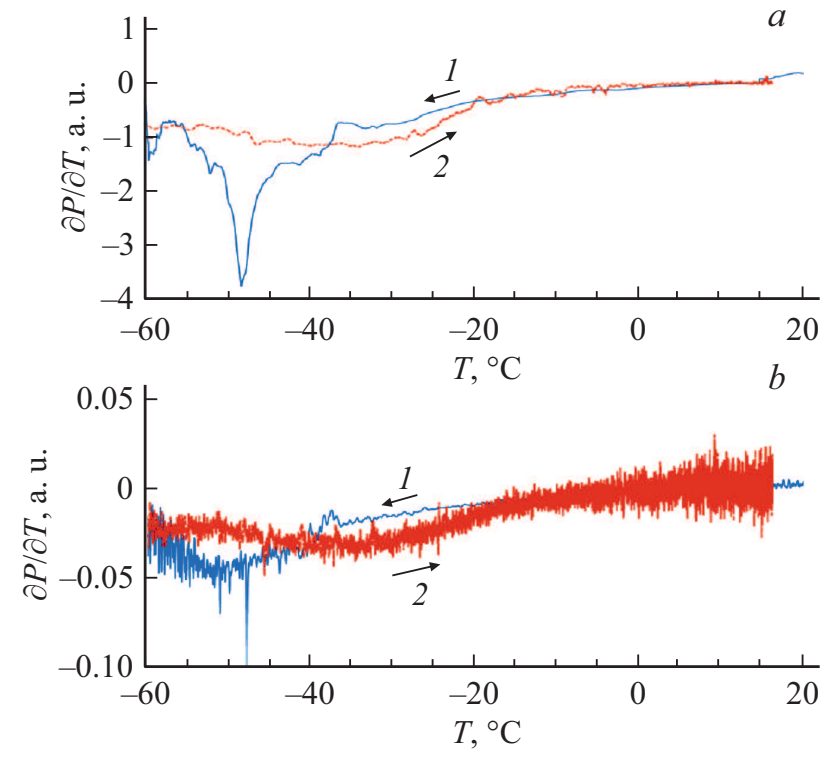

Рис. 2. $a-$ зависимость производной отраженной мощности микроволнового излучения от температуры образца, увлажненного раствором гидроперита, при усреднении в 1000 точках. $b-$ аналогичная зависимость для другого образца при усреднении по 500 точкам. 1 - для участка охлаждения, 2 - для участка нагревания. Стрелками показано направление изменения температуры.

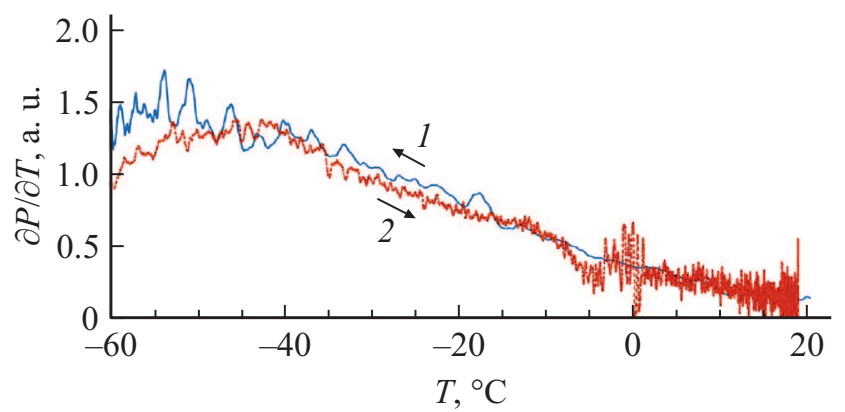

Рис. 3. Зависимость производной $\partial P / \partial T$ от температуры образца, увлажненного раствором перекиси водорода, при усреднении по 100 точкам. Обозначение кривых то же, что на рис. 2. 
ного силикагеля при температурах от -20 до $-40^{\circ} \mathrm{C}$ на основе данных о диэлектрической проницаемости глубоко переохлажденной воды [9] составляет 2-3 mm.

При нахождении производной выполнялось усреднение ее значений для понижения флуктуаций и выделения областей температуры, в которых возникали быстрые изменения электрофизических характеристик. На рис. 2, $a$ экстремум $\partial P / \partial T$ имел место при температуре $-47^{\circ} \mathrm{C}$ для кривой, соответствующей охлаждению образца. Отрицательное значение производной при всех температурах соответствовало возрастанию регистрируемой мощности с понижением температуры, что определяется геометрией образца и значениями действительной и мнимой частей относительной комплексной диэлектрической проницаемости.

Результаты измерений с использованием раствора перекиси водорода, помещаемого в поры силикагеля, приведены на рис. 3. Ее весовая концентрация составила в образце $\sim 6 \%$. Усреднение производной выполнялось по 100 точкам. Экстремумы на зависимостях размыты, наиболее выражен экстремум для случая нагревания среды и приблизительно соответствует $-47^{\circ} \mathrm{C}$. На кривой, соответствующей охлаждению, обнаруживаются дополнительные экстремумы, которые можно связать с существованием двух известных эвтектик [8]. Для данного случая экстремумы растянуты по температуре по сравнению с результатами для увлажнения гидроперитом (рис. 2, $a, b)$.

Объяснение различия данных, полученных при измерениях силикагеля с гидроперитом и раствором в воде чистой перекиси водорода в его порах, следующее. При охлаждении образца (рис. 2, $a, b)$ происходит переохлаждение жидкости, которая находится в метастабильном состоянии. При достижении температуры на линии Видома флуктуации энтропии и плотности приводят к разрушению метастабильного состояния и резкому изменению диэлектрической проницаемости. При обратном процессе происходит медленное таяние образовавшихся в среде кристаллогидратов перекиси водорода. Для случая чистой перекиси ниже $-50^{\circ} \mathrm{C}$ образуются кристаллогидраты в точках эвтектики, их образование обнаруживается по осцилляциям производной. При нагревании образца кристаллогидраты некоторое время остаются в растворах. Их разрушение происходит в широком интервале температур.

Некоторый сдвиг температуры экстремумов $\partial P / \partial T$ $\left(\right.$ на $\sim 1^{\circ} \mathrm{C}$ ) по сравнению с известным значением $-45^{\circ} \mathrm{C}$ при давлении $0.1 \mathrm{MPa}$ для чистой воды связан с использованием растворов, что эквивалентно повышению давления в воде [10,11]. Сдвиг этой температуры при высокой концентрации растворенного вещества в некоторых случаях достигает десятков градусов [7] при сохранении аномалий воды.

Интересной особенностью полученных результатов является проявление эффекта резкого изменения электромагнитных характеристик в узком интервале температур. На исходных графиках в ряде случаев заметны скачки сигналов на интервалах времени порядка минуты. Это напоминает достижение порога активации реакций. Данная особенность, возможно, объясняется взрывной неустойчивостью кристаллов льда [12], что происходит при достижении давления на линии Видома для соответствующей температуры. В [13] было высказано другое предположение о необычных характеристиках воды, согласно которому возможно ускорение химических превращений при достижении условий повышенных флуктуаций энергии водных структур вблизи линии Видома.

Таким образом, в работе показано, что влияние линии Видома может исследоваться не только по изменениям термодинамических величин, но и при микроволновых измерениях характеристик, определяемых диэлектрической проницаемостью сред в метастабильных водных системах.

\section{Конфликт интересов}

Авторы заявляют, что у них нет конфликта интересов.

\section{Список литературы}

[1] G. Franzese, H.E. Stanley, J. Phys.: Condens. Matter, 19 (20), 205126 (2007). DOI: 10.1088/0953-8984/19/20/205126

[2] C.A. Angell, Ann. Rev. Phys. Chem., 34, 593 (1983). DOI: 10.1146/annurev.pc.34.100183.003113

[3] P.H. Handle, T. Loerting, F. Scortino, Proc. Natl. Acad. Sci. USA, 114 (51), 13336 (2017). DOI: $10.1073 /$ pnas. 1700103114

[4] K.H. Kim, A. Späh, H. Pathak, F. Perakis, D. Mariedahl, K. Amann-Winkel, J.A. Sellberg, J.H.L. Kim, J.P.H. Nam, X. Katayama, A. Nilsson, Science, 358 (6370), 1589 (2017). DOI: $10.1126 /$ science.aap8269

[5] Л.И. Меньшиков, П.Л. Меньшиков, П.О. Федичев, ЖЭТФ, 152 (6), 1374 (2017). DOI: 10.7868/S0044451017120215 [L.I. Menshikov, P.L. Menshikov, P.O. Fedichev, JETP, 125 (6), 1173 (2017). DOI: $10.1134 / \mathrm{S} 1063776117120056]$.

[6] S. Cerveny, F. Mallamace, J. Swenson, M. Vogel, L. Xu, Chem. Rev., 116 (13), 7608 (2016). DOI: $10.1021 /$ acs.chemrev.5b00609

[7] S. Woutersen, U. Emmerichs, H.J. Bakker, Science, 278 (5338), 658 (1997). DOI: 10.1126/science.278.5338.658

[8] У. Штамб, Ч. Сеттерфилд, Р. Вентворс, Перекись водорода (ИЛ, М., 1958), с. 183.

[9] G.S. Bordonskiy, A.A. Gurulev, A.O. Orlov, Dielectric permittivity of deeply supercooled water according to the measurement data at the frequencies $7.6 \mathrm{GHz}$ and $9.7 \mathrm{GHz}$, preprint. arXiv: 2005.07001, 6 (2020).

[10] М.А. Анисимов, Сверхкритические флюиды: теория и практика, 7 (2), 19 (2012).

[11] J.W. Biddle, V. Holten, M.A. Anisimov, J. Chem. Phys., 141 (7), 074504 (2014). DOI: 10.1063/1.4892972

[12] Е.Г. Фатеев, ЖТФ, 80 (7), 46 (2010). [E.G. Fateev, Tech. Phys., 55 (7), 958 (2010). DOI: $10.1134 / \mathrm{S} 1063784210070078]$.

[13] Г.С. Бордонский, А.А. Гурулев, Конденсированные среды и межфазные границы, 21 (4), 478 (2019). DOI: $10.17308 / \mathrm{kcmf} .2019 .21 / 2359$ 